\title{
Influence of Crumb-Rubber in the Mechanical Response of Modified Portland Cement Concrete
}

\author{
J. Retama ${ }^{1}$ and A. G. Ayala ${ }^{2}$ \\ ${ }^{1}$ Department of Civil Engineering, FES Aragón, National Autonomous University of Mexico, 57130 Nezahualcoyotl, MEX, Mexico \\ ${ }^{2}$ Department of Structural Engineering, Institute of Engineering, National Autonomous University of Mexico, Coyoacán, \\ 04510 Mexico City, Mexico
}

Correspondence should be addressed to J. Retama; jretamav@comunidad.unam.mx

Received 10 February 2017; Accepted 3 April 2017; Published 2 May 2017

Academic Editor: Peng Zhang

Copyright (C) 2017 J. Retama and A. G. Ayala. This is an open access article distributed under the Creative Commons Attribution License, which permits unrestricted use, distribution, and reproduction in any medium, provided the original work is properly cited.

The influence of crumb-rubber on the mechanical properties of Portland cement concrete (PCC) is studied by experimental tests and numerical simulations. The main hypothesis of the study is that replacing part of the stone aggregate with crumb-rubber in the mix modifies the energy dissipation during the cracking process and affects the concrete behaviour under monotonically increasing loads. The experimental research program characterizes the mechanical properties of PCC for three different types of concrete with a variable content of crumb-rubber. The experimental results showed that fracture energy and other properties are directly related to the rubber fineness used in the mixture. The material properties derived for these laboratory tests are used to study, by numerical models, its response through its damage evolution. The numerical model used to simulate the damage evolution of the concrete is the Embedded Discontinuity Method (EDM). One characteristic of the EDM is that it does not need to modify the mesh topology to propagate the damage through the continuum solid. For this study, the Disk-Shaped Compact Tension specimen geometry, normed by the D7313-13 of the ASTM, is used. Results showed that the numerical methods provide good approximation of the experimental curve in the elastic and softening branches.

\section{Introduction}

Even though concrete is the most common material used in infrastructure construction, like roads, it does not always fulfil requirements like low weight, high strength, and ductility, under working-load conditions. Numerous studies have been conducted to improve the mechanical properties of concrete by replacing part of the aggregate with rubber obtained from discarded tires [1].

1.1. Experimental Studies. Compared with the use of crumbrubber in asphalt paving mixtures, its use in PCC material is limited $[2,3]$.

During the last two decades, studies have investigated possible uses of crumb-rubber from scrap tires [4-6]. One of the most promising applications is the use of such waste, in creating PCC roads $[4,7,8]$. To conduct this process, the tires must be crushed in the form of chips or powder to be incorporated into the concrete.
Khatib and Bayomy [9] performed experimental tests using fine and coarse rubber as stone aggregate replacement in a concrete mix and reported that the rubberized PCC mixes can be fabricated and exhibit workability up to a certain degree, where the maximum rubber replacement content tested was $57 \%$ of the total aggregate volume. Following the same idea, Huang et al. [2] subjected rubberized concrete specimens to uniaxial compression loads; their results showed that this type of concrete exhibits a high toughness. However, the strength decreases significantly when the rubber content increases. With the intention of analysing this phenomenon, Ghaly and Cahill [10] replaced 5\%, 10\%, and $15 \%$ of tire rubber per concrete volume and showed that there is a reduction in the compressive strength in the concrete with a higher rubber content and that, in all cases, the strength of the conventional concrete was superior.

To attenuate the effects of this issue, Papakonstantinou and Tobolski [11] added tire rubber, including the steel cords, 


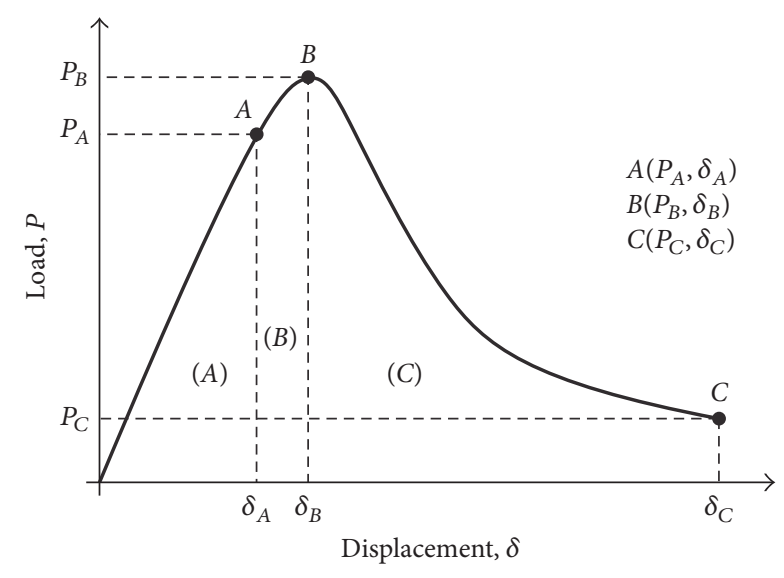

FIGURE 1: Typical load-displacement curve [17].

to the preparation of concrete mixes. Their experimental results showed that, despite a reduction in compressive strength, the toughness increased when the steel reinforcement was included. Using the same approach and greater rubber volumes, Khaloo et al. [12] fabricated rubberized concrete test specimens at percentages of $12.5 \%, 25 \%, 37.5 \%$, and $50 \%$ and subjected them to uniaxial compression tests with controlled deformation, which exhibited significant reductions in the strength and elasticity modulus and an important reduction in the concrete brittle behaviour when the rubber content was increased.

These researchers and others [13-15] studied the energy dissipation in concrete by means of the three points' beam geometry. In the present research work the Disk-Shaped Compact Tension test normed by the ASTM D7313-13 standard [16] is adopted to evaluate the fracture energy of concrete mixes.

1.2. Numerical Studies. In addition to the evaluation of the mechanical properties previously described, understanding the fracture process of rubberized concrete is essential. During the fracture evolution in concrete, there is a release of energy $[18,19]$. Behaviour like that shown in Figure 1 [17] is typical for quasi-brittle materials like concrete.

Due to the nature of rubber, bonding between this and cement paste is weak, resulting in a reduction of compressive and tensile strength of PCC $[1,2,20]$ but an improvement in its ductility in the postyielding behaviour [21].

The idea of modelling the damage process in quasi-brittle materials by lumping strain concentration along a crack has motivated the development of formulations of finite elements with embedded discontinuities and their applications to quasi-static problems. This type of finite elements provides a realistic and direct way to implement constitutive models of cohesive cracks in a continuum setting. Following the pioneering work of Ortiz et al. [22] and Belytschko et al. [23] many related formulations have been published [24-28].

The formulation of these elements implies two requirements in the crack zone which must be satisfied: (1) equilibrium (traction continuity across crack surfaces) and (2)
TABLE 1: Concrete mix design.

\begin{tabular}{lccc}
\hline Material & \multicolumn{3}{c}{ Dosage $\left(\mathrm{kg} / \mathrm{m}^{3}\right)$} \\
Portland cement & 350 & CCR & PCC \\
River sand & 770.2 & 790 & 350 \\
Crushed basalt & 1000 & 975 & 790 \\
Crushed rubber & 19.8 & 25 & 1000 \\
Water & 205 & 205 & 0 \\
\hline
\end{tabular}

kinematics (rigid body motions of the two parts in which the element is divided by a crack) [29].

The application of the Embedded Discontinuity Method (EDM) to study the damage in solids covers different types of materials. In the context of asphalt concrete, in 2005, Wagoner et al. [30] used an intrinsic cohesive zone model, in which the bulk of the material was discretized with linear elastic finite elements, whereas the crack zone was modelled with cohesive interface elements. The constitutive behaviour of the material of these interface elements was considered using a bilinear softening law. In $2009 \mathrm{Wu}$ et al. [31] applied the EDM to accurately reproduce the fracture behaviour of a Disk-Shaped Compact Tension test. These authors used the model proposed by Sancho et al. [32] which was implemented through the finite element method (FEM) into the open source software OpenSees [33].

In the present paper, the capabilities of the EDM are shown for modelling the damage process in disk-shaped compact specimens, built of concrete mixtures with different amounts of tire rubber aggregate, based in the EDM formulated by Retama and Ayala [28].

\section{Materials and Experimental Program}

For this study, three types of concrete were studied: concrete with fine crumb-rubber (CFR), concrete with coarse crumbrubber (CCR), and, as comparison material, Portland cement concrete (PCC), without crumb-rubber.

2.1. Concrete Mix Design. To fabricate the concrete mix, conventional Portland cement combined with a coarse aggregate (crushed basalt rock) with a maximum size of $20 \mathrm{~mm}$ and fine aggregate (river sand) with a maximum diameter of $5 \mathrm{~mm}$ was used.

The crumb-rubber was incorporated into the concrete mix to replace the stone aggregate (fine or coarse depending on the case) in a proportion of $2.5 \%$ per weight. The mix proportions for the three types of concrete are shown in Table 1.

2.2. Fabrication of Specimens. A total of 30 concrete cylinders with diameters of $15 \mathrm{~cm}$ and heights of $15 \mathrm{~cm}$ (10 cylinders for each type of concrete) were cut with a saw to obtain the DiskCompact Tension test (DCT). In Figure 2 the geometry of the specimens standardized by the ASTM D7313-13 standard can be seen [16].

Characteristic dimensions of the specimen are shown in Figure 2, and their numerical values are as follows: 


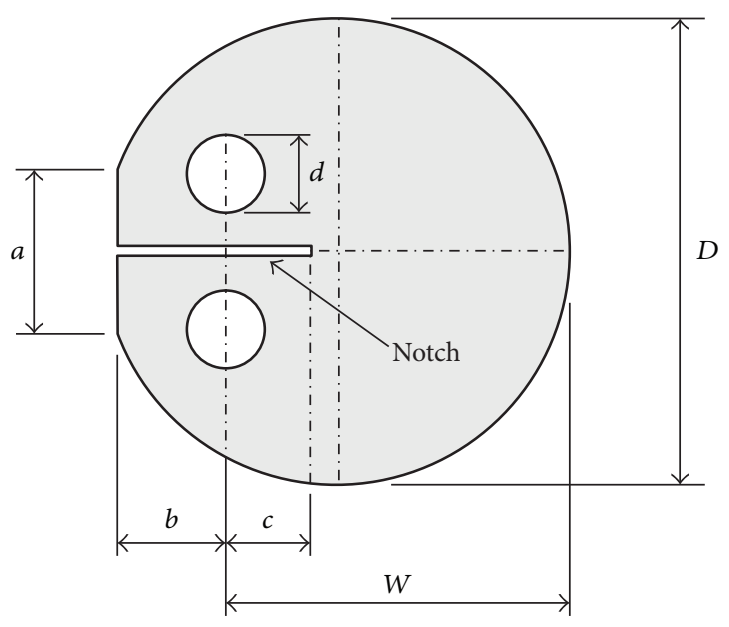

FIGURE 2: DCT specimen geometry.

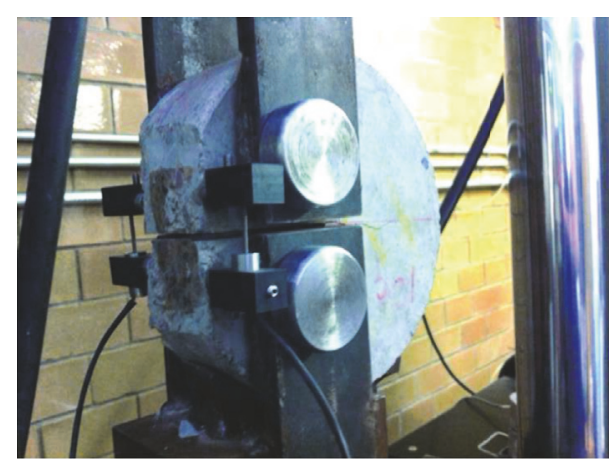

FIGURE 3: Specimen mounted in the machine test.

(i) $D=150 \mathrm{~mm}$

(ii) $d=25 \mathrm{~mm}$

(iii) $a=50 \mathrm{~mm}$

(iv) $b=35 \mathrm{~mm}$

(v) $c=27.50 \mathrm{~mm}$

(vi) $W=110 \mathrm{~mm}$

(vii) depth $=5 \mathrm{~mm}$.

A total of 10 specimens were tested for each concrete, that is, concrete with fine crumb-rubber, concrete with coarse crumb-rubber, and concrete without crumb-rubber.

2.3. Test Method. During the DCT test, a servohydraulic press was used to apply the load along with a pair of LVDTs to measure the specimen crack mouth opening displacement (CMOD); see Figure 3. The LVDTs were positioned on both lateral faces of the specimen to obtain an average of the aperture. At the beginning of the test, a preload of $0.2 \mathrm{kN}$ was applied, and subsequently, a controlled displacement of $0.0017 \mathrm{~mm} / \mathrm{s}$ was applied until failure.

The execution speed of the test was ten times slower than that specified by the ASTM D7313 standard $(0.017 \mathrm{~mm} / \mathrm{s})$ because, in contrast with an asphalt mix, concrete exhibits a brittle failure, which makes it difficult to collect information from a load-CMOD curve at a fast speed. Several additional tests were performed at a speed of $0.00017 \mathrm{~mm} / \mathrm{s}$ (one hundred times slower than that specified in the ASTM D7313 standard). The results obtained were unsatisfactory because an elastic recovery phenomenon occurred in the concrete. All specimens were tested at $10^{\circ} \mathrm{C} \pm 0.2^{\circ} \mathrm{C}$.

\section{Embedded Discontinuity Method}

The EDM addressed in this paper, for modelling the kinematic behaviour of a finite element crossed by a cohesive crack, that is, crack line in which all damage process zone is lumped and characterized in the form of a traction-displacement law which exhibits softening, corresponds to that developed by Retama and Ayala [28].

In this method, the two parts in which a finite element is divided by a cohesive crack, referred to in this paper as a discontinuity, are assumed to undergo rigid body motions with respect to the kinematics of the discontinuity as it is shown in Figure 4.

To illustrate the method, Figure 4 shows a triangular finite element divided into two parts, $V^{-}$and $V^{+}$, by the discontinuity $S_{d}$, defined by its normal vector $\mathbf{n}$ pointing towards $V^{+}$, and the relative displacements between both subdomains are given by the displacements jump vector $\llbracket \mathbf{u} \rrbracket=\left(\llbracket u \rrbracket_{n} \llbracket u \rrbracket_{s}\right)^{T}$.

The standard kinematics of the finite element is enriched at elemental level, by introducing an internal node where displacements jump $\llbracket \mathbf{u} \rrbracket$ is defined as a constant function. According to this, the element displacement field is decomposed into elastic, $\mathbf{u}^{e}$, and cracking, $\mathbf{u}^{c}$, parts

$$
\mathbf{u}=\mathbf{u}^{e}+\mathbf{u}^{c}
$$

The elastic displacement part is a smooth function defined in the element domain $V$ as

$$
\mathbf{u}^{e}=\mathbf{N d}
$$

In (2), matrix $\mathbf{N}$ contains the standard shape functions used to interpolate the element nodal displacements $\mathbf{d}$ [34]. In the same way, cracking displacements are interpolated in the finite element framework by means of

$$
\mathbf{u}^{c}=\mathbf{N}_{c} \llbracket \mathbf{u} \rrbracket,
$$

with $\mathbf{N}_{c}$ being a shape functions matrix associated with nodes located in $V^{+}$(see Figure 4) and the already defined displacement jump vector $\llbracket \mathbf{u} \rrbracket$, both defined at elemental internal node. For the case of the node numbering of the triangle shown in Figure 4, the matrix $\mathbf{N}_{c}$ is defined as

$$
\mathbf{N}_{c}=\sum_{i=1}^{n^{+}} N_{i}^{+}=N_{3},
$$

where $n^{+}$denotes the number of nodes belonging to the subdomain $V^{+}$. For a detailed description of the EDM, the reader is referred to the work of Retama [27]. 

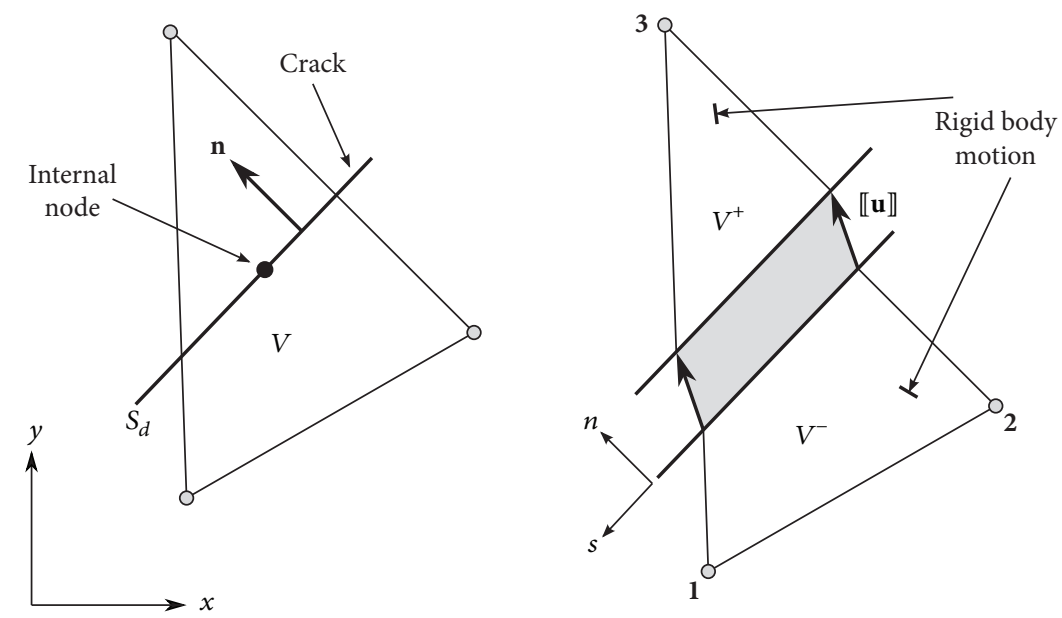

FIgURE 4: Finite element with internal crack.

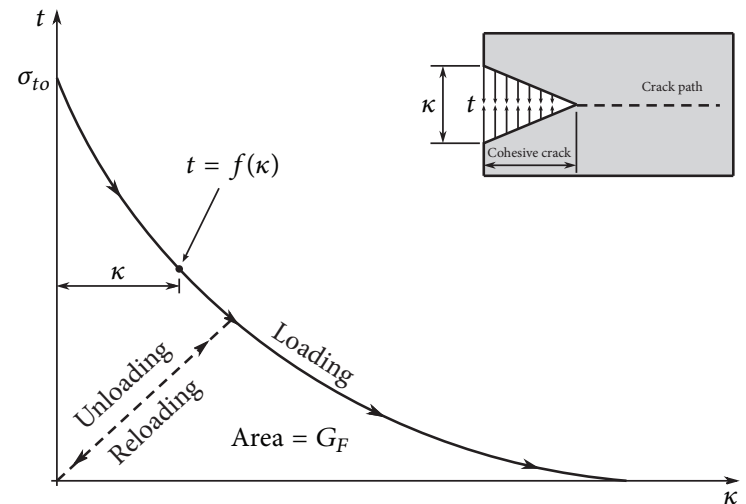

FIGURE 5: Cohesive crack model.

3.1. Cohesive Damage Model. For modelling the evolution of material damage where mode-I type failure is dominant, altogether with the EDM, a cohesive crack type model is used $[18,35,36]$. The effects of microcracks and plastic flow around a macroscopic crack tip are introduced as equivalent tractions along the crack faces, as it is shown in Figure 5. This cohesive crack model was introduced by Barenblatt [37] and Dugdale [38] for modelling cracks in materials such as ceramics, polymers, and metals and extended to concrete by Hillerborg et al. [36].

In this model, the inelastic response is governed by two key material parameters: tensile strength, $\sigma_{t o}$, and fracture energy, $G_{F}$, Figure 5. A discontinuity is introduced when the principal stress $\sigma_{I}$ exceeds the tensile strength of the material, like the Rankine criterion in classical plasticity theory, which is a mode-I of failure criterion commonly used for quasibrittle materials $[39,40]$.

Following the work of Retama and Ayala [27, 28], the function $f$ which describes the load state in the crack zone, loading/unloading conditions, is given as

$$
f=\left\langle\llbracket u \rrbracket_{\mathrm{eq}}-\kappa \leq 0\right\rangle,
$$

where $\llbracket u \rrbracket_{\text {eq }}$ is an equivalent jump obtained from the displacement jump vector $\llbracket \mathbf{u} \rrbracket$. The symbol $\langle\cdot\rangle$ represents the Macauley brackets, denoting that only the positive part of the normal displacement jump is considered, and $\kappa$ is a scalar internal variable, equal to the largest value of $\left\langle\llbracket u \rrbracket_{\text {eq }}\right\rangle$, defined as

$$
\kappa=\kappa \llbracket \mathbf{u} \rrbracket=\max \left\langle\llbracket u \rrbracket_{\text {eq }}\right\rangle .
$$

Tractions on the discontinuity surface are functions of the normal displacement jump, through $\kappa$. These are derived from the classical softening curve, Figure 5, by means of the exponential function

$$
t_{n}=\sigma_{t o} e^{\left(-\left(\sigma_{t o} / G_{F}\right) \kappa\right)} .
$$

This equation implies that the residual traction has the same direction as the jump displacement, that is, monotonic loading state. Furthermore, (7) considers that the energy dissipation in the damage process is consistent with the physical phenomena, since

$$
G_{F}=\int_{0}^{\infty} t_{n} d \kappa
$$

To complete the constitutive relation for the material in the crack zone, it is necessary to define the tangent constitute tensor $\mathbf{T}$. This is derived from (8) as

$$
\mathbf{T}=\frac{\partial t}{\partial \kappa}=-\frac{\sigma_{t o}^{2}}{G_{F}} e^{\left(-\left(\sigma_{t o} / G_{F}\right) \kappa\right)} .
$$

\section{Numerical Simulation}

The aim of this section is to show the ability of the EDM to reproduce experimental results under quasi-static loading conditions, showing its numerical and theoretical consistency. Since no shear stresses are allowed along the crack, damage is simulated considering only the mode-I of failure.

The EDM, presented in Section 3, was implemented in the FEAP program. Taking advantage of the enriched element 


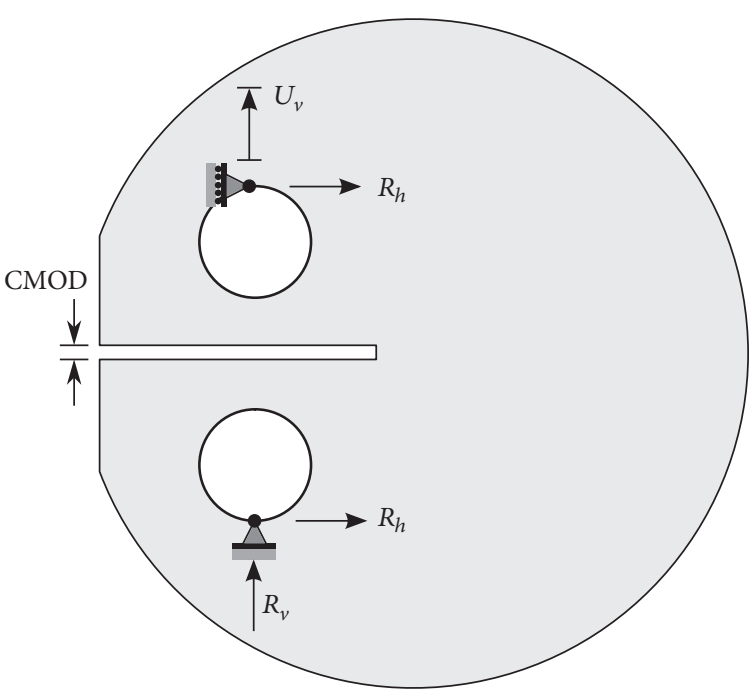

(a)

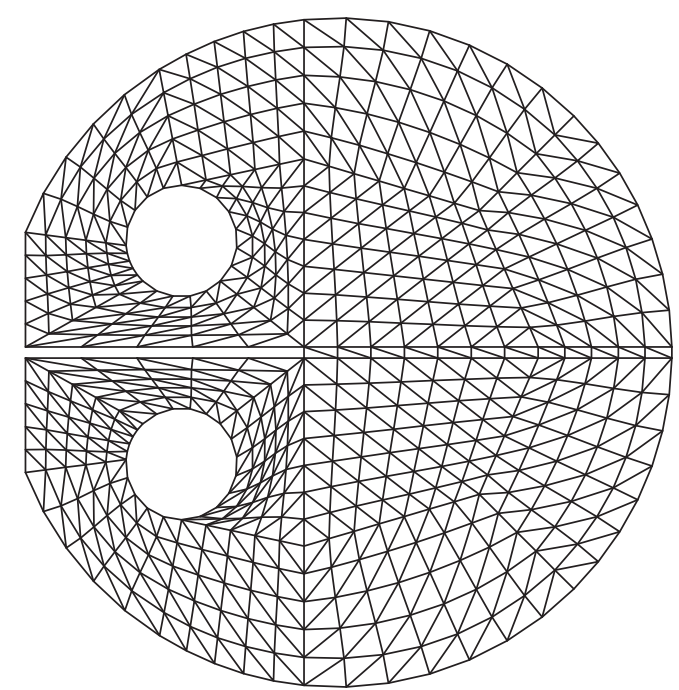

(b)

FIGURE 6: Finite element model, (a) supports, and (b) mesh.

used to incorporate the crack into the element domain, static condensation of the additional degrees of freedom (dof) was used to preserve those regular in a standard finite element formulation $[27,41]$.

4.1. Geometry. The specimen geometry used corresponds to that described in Section 2.2 for the experimental test, following recommendations of the ASTM D7313 standard; see Figure 2.

The geometry of the specimen includes a notch symmetrically located between the two holes where displacements are imposed. This notch is to guarantee that damage initiates at its tip and the plastic zone around is minimum.

4.2. Finite Element Model. To simulate the test conditions of the specimen, a plane stress state was considered. The used supports are shown in Figure 6(a). In the lower support, zero horizontal and vertical displacements were considered, whereas in the upper one, zero horizontal displacement was imposed and in the vertical direction, an incremental displacement control was applied. The finite element mesh used, shown in Figure 6(b), consisted of constant strain triangles with embedded discontinuities.

Elastic and fracture energy properties, used in the numerical simulation, are given in Sections 5.1 and 5.2.

\section{Results and Discussions}

This section presents results derived from the experimental and numerical studies, for the three concrete mixes, pointing out in the curve load versus CMOD and the energy dissipation in the damage evolution process.

5.1. Elastic Properties. Additional specimen to those used to obtain the fracture energy were tested according to the ASTM standards: for elastic modulus, C469 [42], compressive strength, C39 [43], and tensile strength, C496 [44]. The results are shown in Table 2.

The average properties taken for the numerical simulation, described in Section 4, are those reports in Table 2, and the Poisson ration is equal to $v=0.20$, for the three types of concrete.

It is observed that the size of crumb-rubber modifies the elastic properties of the concrete. The elastic modulus of concrete CCR is less than those for CFR and PCC; this means that the material undergoes more deformation before the yield strength is reached, that is, increasing the ductility of the material, but its tensile strength is reduced in $16.7 \%$ with respect to PCC.

This behaviour of CFR is attributed to the capability of crumb-rubber to deform and its lack of adherence with the cement past.

5.2. Fracture Energy. Results of experimental tests for the three concrete mixes are reported in this section. The measured fracture energy is associated with the mode-I of failure, dominant in this series of tests. Curves of load versus CMOD for CFR, CCR, and PCC concrete are shown in Figures 7, 8, and 9 , respectively.

Values of peak load, maximum CMOD, and fracture energy for the ten specimens, for each concrete type, are shown in Tables 3-5.

Comparing results of specimens with the two crumbrubber sizes, we may observe reductions in the maximum load peak and CMOD for the concrete CFR, which is reflected in a reduced total fracture energy value; that is, the fine rubber creates more imperfections in the concrete that increases its brittleness. In the concrete with coarse rubber, imperfections occur but to a lesser extent because rubber is less dispersed throughout the mix.

5.3. Numerical versus Experimental Results. In this section the results obtained from the numerical simulation are 
TABLE 2: Elastic properties.

\begin{tabular}{|c|c|c|c|c|c|c|}
\hline \multirow{2}{*}{ Specimen } & \multicolumn{2}{|c|}{ Compressive strength } & \multicolumn{2}{|c|}{ Tensile strength } & \multicolumn{2}{|c|}{ Elastic modulus } \\
\hline & $\mathrm{MPa}$ & Std. dev. & MPa & Std. dev. & $\mathrm{GPa}$ & Std. dev. \\
\hline CFR & 24.51 & 4.21 & 3.23 & 2.45 & 20.51 & 0.50 \\
\hline CCR & 24.90 & 4.89 & 2.94 & 3.62 & 19.99 & 0.59 \\
\hline PCC & 25.06 & 3.14 & 3.53 & 2.58 & 26.50 & 0.61 \\
\hline
\end{tabular}

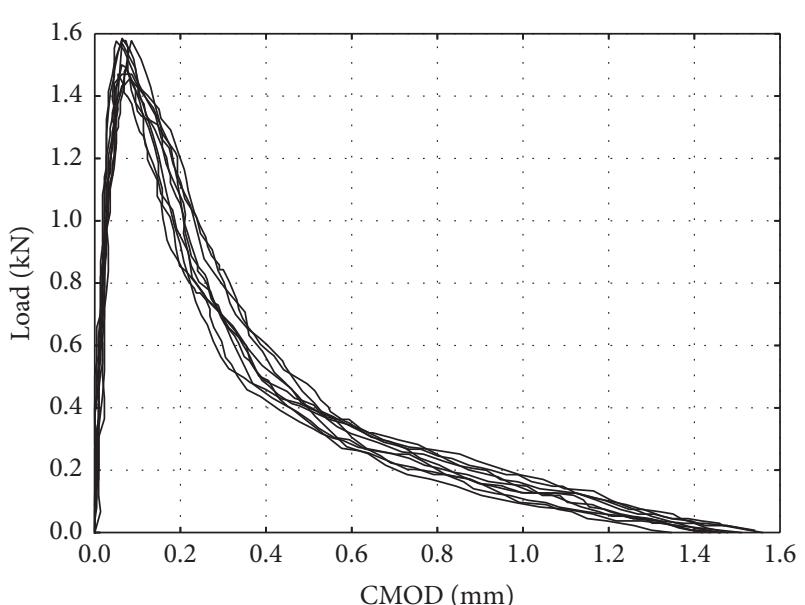

FIgURE 7: Fracture energy for CFR.

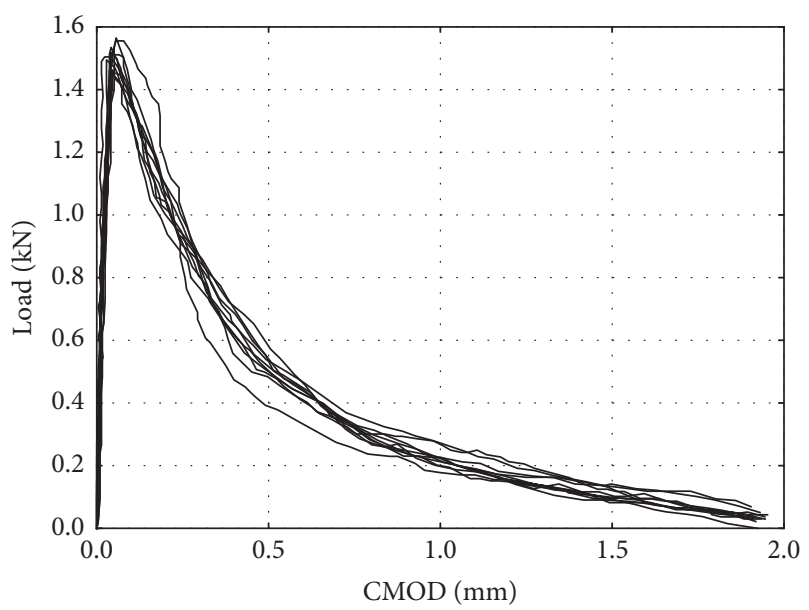

FIGURE 8: Fracture energy for CCR.

compared with those obtained from experimental tests, pointing out in the characteristics of the softening curve for each concrete mix.

Once the damage propagates, as is shown in Figure 10, the crack divides the solid in two parts. This phenomenon is shown in Figure 10(b) in which both subdomains unload elastically without energy dissipation.

The numerical responses represented by the load versus CMOD curves for the three types of materials, that is, CFR, CCR, and PCC, are shown in Figures 11-13, respectively. In these curves, the experimental data are plotted within the

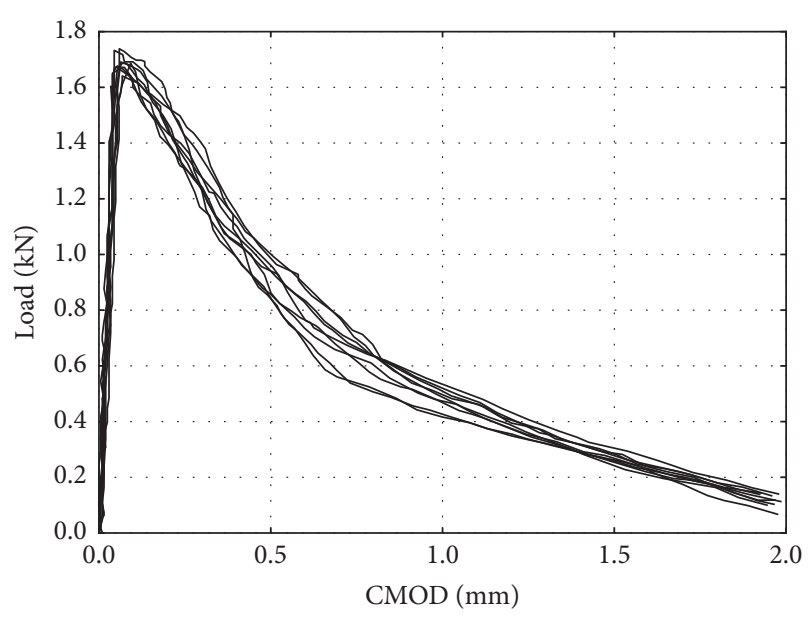

FIgURE 9: Fracture energy for PCC.

TABLE 3: Fracture energy for specimens of CFR.

\begin{tabular}{lccc}
\hline Specimen & $P_{L}$ & $\begin{array}{c}\mathrm{CMOD}_{\max } \\
(\mathrm{mm})\end{array}$ & $\begin{array}{c}G_{F} \\
(\mathrm{~N} / \mathrm{m})\end{array}$ \\
\hline CFR-1 & 1.470 & 1.459 & 151.943 \\
CFR-2 & 1.455 & 1.477 & 143.380 \\
CFR-3 & 1.576 & 1.558 & 153.387 \\
CFR-4 & 1.585 & 1.417 & 135.700 \\
CFR-5 & 1.470 & 1.531 & 124.708 \\
CFR-6 & 1.577 & 1.509 & 133.638 \\
CFR-7 & 1.555 & 1.490 & 136.615 \\
CFR-8 & 1.577 & 1.418 & 130.827 \\
CFR-9 & 1.500 & 1.472 & 129.524 \\
CFR-10 & 1.492 & 1.540 & 142.878 \\
\hline Avg. & 1.526 & 1.487 & 138.260 \\
Std. dev. & 0.052 & 0.048 & 9.483 \\
\hline
\end{tabular}

grey areas, while those obtained with the EDM are plotted as a dark continuous curve.

From these curves, it is observed that the ascending branch, for all three materials, is well reproduced by the numerical simulation, that is, Embedded Discontinuity Method. Regarding the softening branch, the best numerical approximation to the experimental data is for the concrete without crumb-rubber PCC. This was not the case for the concrete with crumb-rubber, a fact that may be explained by the influence of the high heterogeneity, present in these types of concrete, on a numerical formulation assuming homogeneous material. Nevertheless, as it is observed in 


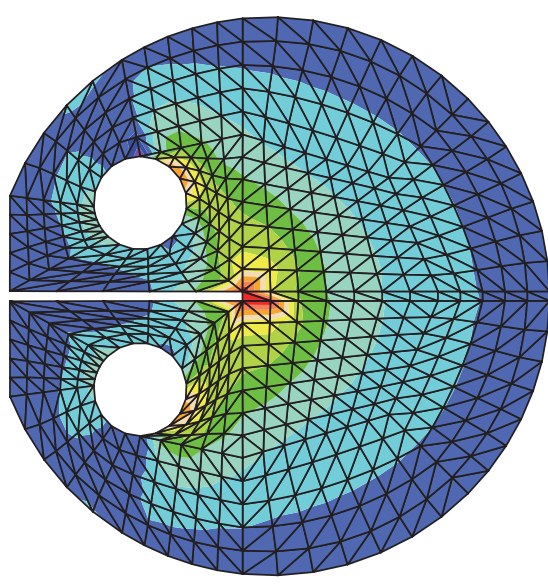

(a)

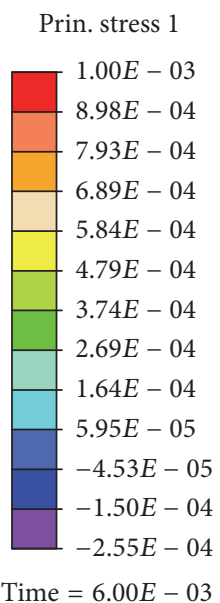

Time $=6.00 E-03$

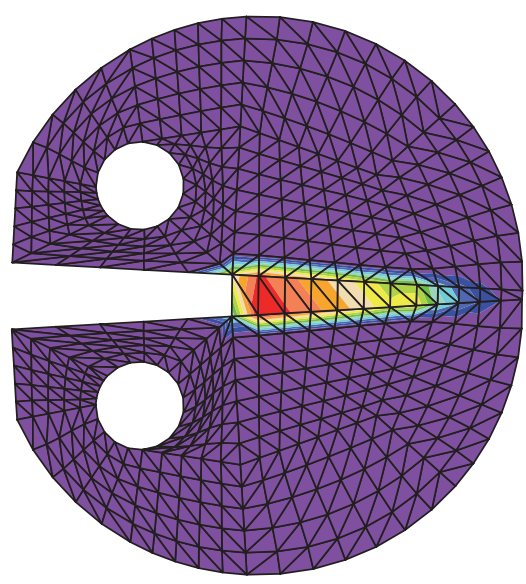

(b)

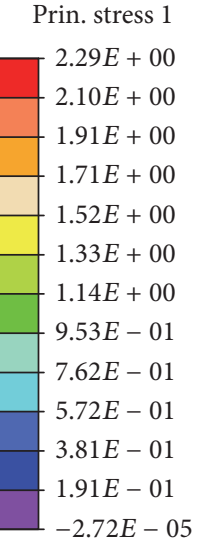

Time $=1.25 E+00$

FIgURE 10: Principal stress $\sigma_{I}$, (a) at the initiation damage, and (b) at a total damage state.

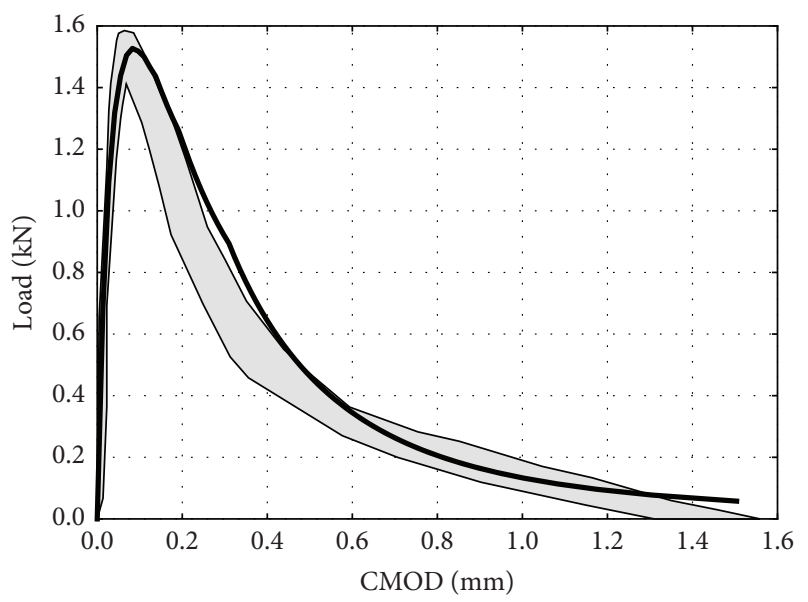

Experimental

Numerical

FIGURE 11: CFR concrete.

the softening curve for each modified concrete, the highest difference of the numerical results with the experimental curve corresponds to the concrete CCR, Figure 12.

In general, the difference in numerical and experimental curves may be related to fact that concrete materials, modified or not, are highly heterogeneous and their characterization is difficult.

\section{Conclusions}

A series of experimental tests for two types of Portland cement concrete, modified with crumb-rubber, and those without crumb-rubber, were conducted to obtain elastic properties and fracture energy for mode-I of failure. Additional numerical studies, based on the Embedded Discontinuity Method, were used to simulate the mechanical behaviour of the material. Some important conclusions may

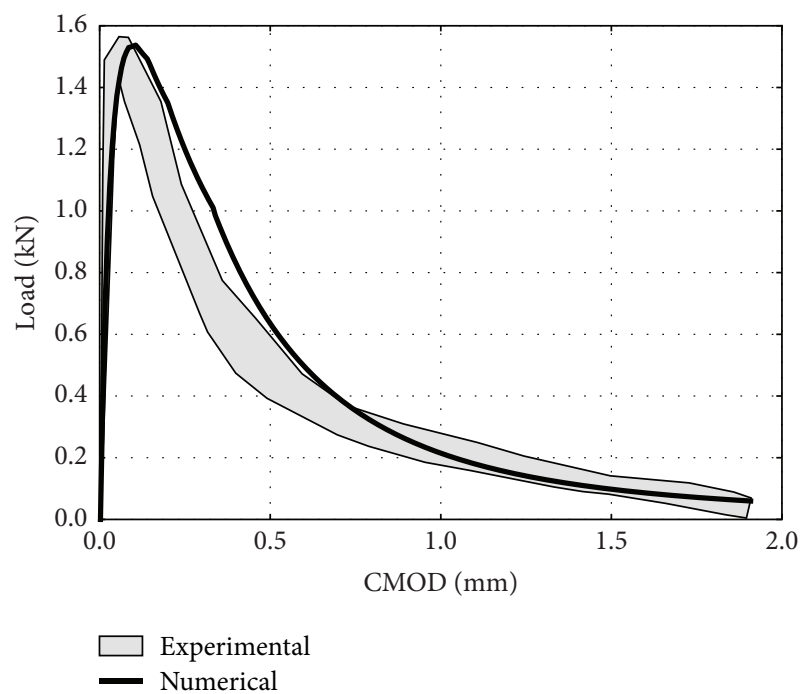

FIgURE 12: CCR concrete.

be addressed in the influence of crumb-rubber and the performance of the presented numerical method.

(i) The size of the crumb-rubber influences the elastic modulus of the concrete, reducing it for the CFR material and enhancing its ductility.

(ii) Another effect due to the use of coarse crumb-rubber is that it causes a reduction of $16.7 \%$ of the tensile strength.

(iii) From curves load-CMOD, it may be observed that the concrete with coarse crumb-rubber presents a better behaviour in the softening branch of the curve, since it deforms almost the same as the PCC concrete but with a reduction of the peak load.

(iv) The difference between results for CFR and CCR may be attributed to the capability of coarse crumb-rubber 


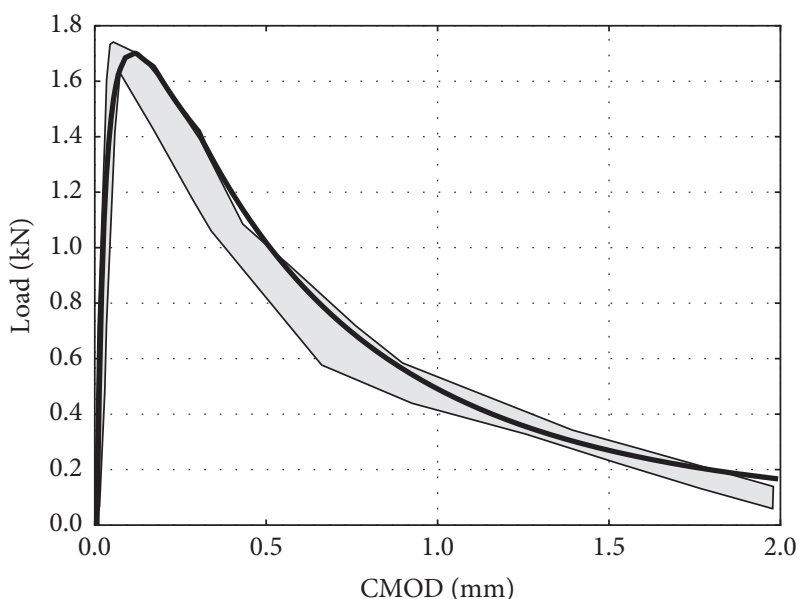

$\square$ Experimental

Numerical

Figure 13: PCC concrete.

TABLE 4: Fracture energy for specimens of CCR.

\begin{tabular}{lccc}
\hline Specimen & $\begin{array}{c}P_{L} \\
(\mathrm{kN})\end{array}$ & $\begin{array}{c}\mathrm{CMOD}_{\max } \\
(\mathrm{mm})\end{array}$ & $\begin{array}{c}G_{F} \\
(\mathrm{~N} / \mathrm{m})\end{array}$ \\
\hline CCR-1 & 1.463 & 1.923 & 169.504 \\
CCR-2 & 1.555 & 2.045 & 178.631 \\
CCR-3 & 1.455 & 1.991 & 167.883 \\
CCR-4 & 1.504 & 2.050 & 186.118 \\
CCR-5 & 1.519 & 2.032 & 180.508 \\
CCR-6 & 1.534 & 2.077 & 176.017 \\
CCR-7 & 1.565 & 2.072 & 185.607 \\
CCR-8 & 1.461 & 2.067 & 182.898 \\
CCR-9 & 1.511 & 2.063 & 157.560 \\
CCR-10 & 1.495 & 2.007 & 171.737 \\
\hline Avg. & 1.506 & 2.033 & 175.646 \\
Std. dev. & 0.039 & 0.048 & 9.034 \\
\hline
\end{tabular}

TABLE 5: Fracture energy for specimens of PCC.

\begin{tabular}{lccc}
\hline Specimen & $\begin{array}{c}P_{L} \\
(\mathrm{kN})\end{array}$ & $\begin{array}{c}\mathrm{CMOD}_{\max } \\
(\mathrm{mm})\end{array}$ & $\begin{array}{c}G_{F} \\
(\mathrm{~N} / \mathrm{m})\end{array}$ \\
\hline PCC-1 & 1.641 & 2.361 & 299.241 \\
PCC-2 & 1.861 & 2.346 & 291.418 \\
PCC-3 & 1.691 & 2.310 & 299.868 \\
PCC-4 & 1.666 & 2.411 & 305.065 \\
PCC-5 & 1.672 & 2.263 & 303.327 \\
PCC-6 & 1.687 & 2.242 & 289.008 \\
PCC-7 & 1.677 & 2.356 & 316.717 \\
PCC-8 & 1.733 & 2.375 & 282.523 \\
PCC-9 & 1.738 & 2.505 & 292.963 \\
PCC-10 & 1.687 & 2.285 & 290.294 \\
\hline Avg. & 1.705 & 2.345 & 297.042 \\
Std. dev. & 0.062 & 0.077 & 9.848 \\
\hline
\end{tabular}

to deform and its lack of adherence with the cement paste.

(v) With respect to the performance of the numerical method to simulate the damage evolution, it is important to point out that, unlike fracture mechanics, it does not require the medication of the mesh topology to accommodate the crack in the solid, once it propagates.

(vi) The presented Embedded Discontinuity Method reproduces the experimental curve with a good approximation, as well as the correct dissipation of energy according to the physical phenomena.

(vii) Other sources of variation of numerical results with those experimental ones may be attributed to the characterization of concrete as a homogenous material.

\section{Conflicts of Interest}

The authors of this paper declare that there are no conflicts of interest regarding its publication.

\section{Acknowledgments}

This research was developed with the support of the "Dirección de Asuntos del Personal Académico (DGAPA)" of the National Autonomous University of Mexico, through the project Análisis No-Lineal de Vigas con Zonas de Plastificación y Funciones Spline, PAPIIT TA101317.

\section{References}

[1] I. B. Topçu, "The properties of rubberized concretes," Cement and Concrete Research, vol. 25, no. 2, pp. 304-310, 1995.

[2] B. Huang, G. Li, S.-S. Pang, and J. Eggers, "Investigation into waste tire rubber-filled concrete," Journal of Materials in Civil Engineering, vol. 16, no. 3, pp. 187-194, 2004.

[3] X. Shu and B. Huang, "Recycled of waste tire rubber in asphalt and portland cement concrete: an overview," Construction and Building Materials, vol. 67, pp. 217-224, 2014.

[4] N. N. Eldin and A. B. Senouci, "Use of scrap tires in road construction," Journal of Construction Engineering and Management, vol. 118, no. 3, pp. 561-576, 1992.

[5] N. N. Eldin and J. A. Piekarski, "Scrap tires: management and economics," Journal of Environmental Engineering, vol. 119, no. 6, pp. 1217-1232, 1993.

[6] D. H. DeGroot, "Mexico-US cross-border resolution of waste tire disposal," in Proceedings of the Worlds Environmental and Water Resources Congress, 2007.

[7] M. K. Batayneh, I. Marie, and I. Asi, "Promoting the use of crumb rubber concrete in developing countries," Waste Management, vol. 28, no. 11, pp. 2171-2176, 2008.

[8] D. Humphrey and M. Blumenthal, "The use of tire-derived aggregated in road construction applications," in Proceedings of the Green Streets and Highways Conference, pp. 299-313, 2010.

[9] Z. K. Khatib and F. M. Bayomy, "Rubberized Portland cement concrete," Journal of Materials in Civil Engineering, vol. 11, no. 3, pp. 206-213, 1999. 
[10] A. M. Ghaly and J. D. Cahill IV, "Correlation of strength, rubber content, and water to cement ratio in rubberized concrete," Canadian Journal of Civil Engineering, vol. 32, no. 6, pp. 10751081, 2005.

[11] C. G. Papakonstantinou and M. J. Tobolski, "Use of waste tire steel beads in Portland cement concrete," Cement and Concrete Research, vol. 36, no. 9, pp. 1686-1691, 2006.

[12] A. R. Khaloo, M. Dehestani, and P. Rahmatabadi, "Mechanical properties of concrete containing a high volume of tire-rubber particles," Waste Management, vol. 28, no. 12, pp. 2472-2482, 2008.

[13] A. Grinys, H. Sivilevičius, D. Pupeikis, and E. Ivanauskas, "Fracture of concrete containing crumb rubber," Journal of Civil Engineering and Management, vol. 19, no. 3, pp. 447-455, 2013.

[14] Y. C. Guo, J. H. Zhang, G. Chen, G. M. Chen, and Z. H. Xie, "Fracture behaviors of a new steel fiber reinforced recycled aggregate concrete with crumb rubber," Construction and Building Materials, vol. 53, pp. 32-39, 2014.

[15] T. Sadowski and D. Pietras, "Description of degradation process of rubberized lean concrete," Solid State Phenomena, vol. 216, pp. 67-72, 2014.

[16] ASTM D7313-13, "Standard test method for determining fracture energy of asphalt aggregate mixtures using the disk-shaped compact tension geometry", American Society for Testing and Materials, 2013.

[17] S. Ribeiro, E. M. B. Santos, G. C. R. Garcia, and J. A. Rodrigues, "Elastic work and fracture energy of concretes made with crushed stones and pebbles aggregates," Materials Science Forum, vol. 636-637, pp. 1215-1221, 2010.

[18] Z. P. Bazant and J. Planas, Fracture and size effect in concrete and other quasibrittle materials, CRC Press, 1997.

[19] T. L. Anderson, Fracture mechanics. fundamentals and applications, CRC Press, 2017.

[20] D. Lo Presti, "Recycled tyre rubber modified bitumens for road asphalt mixtures: a literature review," Construction and Building Materials, vol. 49, pp. 863-881, 2013.

[21] G. Li, M. A. Stubblefield, G. Garrick, J. Eggers, C. Abadie, and B. Huang, "Development of waste tire modified concrete," Cement and Concrete Research, vol. 34, no. 12, pp. 2283-2289, 2004.

[22] M. Ortiz, Y. Leroy, and A. Needleman, "A finite element method for localized failure analysis," Computer Methods in Applied Mechanics and Engineering, vol. 61, no. 2, pp. 189-214, 1987.

[23] T. Belytschko, J. Fish, and B. E. Engelmann, "A finite element with embedded localization zones," Computer Methods in Applied Mechanics and Engineering, vol. 70, no. 1, pp. 59-89, 1988.

[24] J. C. Simo and M. S. Rifai, "A class of mixed assumed strain methods and the method of incompatible modes," International Journal for Numerical Methods in Engineering, vol. 29, no. 8, pp. 1595-1638, 1990.

[25] J. C. Simo, J. Oliver, and F. Armero, "An analysis of strong discontinuities induced by strain-softening in rate-independent inelastic solids," Computational Mechanics, vol. 12, no. 5, pp. 277-296, 1993.

[26] J. Oliver, "Modelling strong discontinuities in solid mechanics via strain softening constitutive equations. Part 1: Fundamentals," International Journal for Numerical Methods in Engineering, vol. 39, no. 21, pp. 3575-3600, 1996.

[27] J. Retama, Formulation and approximation to problems in solids by embedded discontinuity models, National Autonomous University of Mexico, Mexico City, Mexico, 2010.
[28] J. Retama and A. G. Ayala, "Modelado del daño en sólidos mediante formulaciones variacionales y discontinuidades interiores," Revista Internacional de Métodos Numéricos para Cálculo y Diseño en Ingeniería, vol. 26, pp. 171-177, 2010.

[29] M. Jirásek, "Comparative study on finite elements with embedded discontinuities," Computer Methods in Applied Mechanics and Engineering, vol. 188, no. 1, pp. 307-330, 2000.

[30] M. P. Wagoner, W. G. Buttlar, and G. H. Paulino, "Disk-shaped compact tension test for asphalt concrete fracture," Experimental Mechanics, vol. 45, no. 3, pp. 270-277, 2005.

[31] R. Wu, E. Denneman, and J. Harvey, "Evaluation of embedded discontinuity method for finite element analysis of cracking of hot-mix asphalt concrete," Journal of the Transportation Research Board, vol. 2127, pp. 82-89, 2009.

[32] J. M. Sancho, J. Planas, D. A. Cendón, E. Reyes, and J. C. Gálvez, "An embedded crack model for finite element analysis of concrete fracture," Engineering Fracture Mechanics, vol. 74, no. 1-2, pp. 75-86, 2007.

[33] S. Mazzoni, F. McKenna, F. Scott, and G. Fenves, Open System for Earthquake Engineering Simulation, User Command-Language Manual, Pacific Earthquake Engineering Research Center, University of California, Berkeley, Calif, USA, 2008.

[34] O. C. Zienkiewicz, R. L. Taylor, and J. Z. Zhu, "The finite element method. volume 1: its basis and fundamentals," Butterworth-Heinemann, 2005.

[35] R. de Borst, M. A. Gutiérrez, G. N. Wells, J. J. C. Remmers, and H. Askes, "Cohesive-zone models, higher-order continuum theories and reliability methods for computational failure analysis," International Journal for Numerical Methods in Engineering, vol. 60, no. 1, pp. 289-315, 2004.

[36] A. Hillerborg, M. Modéer, and P.-E. Petersson, "Analysis of crack formation and crack growth in concrete by means of fracture mechanics and finite elements," Cement and Concrete Research, vol. 6, no. 6, pp. 773-781, 1976.

[37] G. I. Barenblatt, "The Mathematical Theory of Equilibrium Cracks in Brittle Fracture," Advances in Applied Mechanics, vol. 7, no. C, pp. 55-129, 1962.

[38] D. S. Dugdale, "Yielding of steel sheets containing slits," Journal of the Mechanics and Physics of Solids, vol. 8, no. 2, pp. 100-104, 1960.

[39] J. Alfaiate, G. N. Wells, and L. J. Sluys, "On the use of embedded discontinuity elements with crack path continuity for mode-I and mixed-mode fracture," Engineering Fracture Mechanics, vol. 69, no. 6, pp. 661-686, 2002.

[40] G. N. Wells, Discontinuous modelling of strain localization and failure [Ph.D. thesis], Delft University of Technology, Delft, The Netherlands, 2001.

[41] R. L. Taylor, FEAP: a finite element analysis program, theory manual, University of California, Berkeley, Calif, USA, 2008.

[42] ASTM C469, "Standard test method for static modulus of elasticity and Poisson's ratio of concrete in compression," American Society for Testing and Materials, 2014.

[43] ASTM C39, "Standard test method for compressive strength of cylindrical concrete specimens," American Society for Testing and Materials, 2014.

[44] ASTM C496, "Standard test method for splitting tensile strength of cylindrical concrete specimens," American Society for Testing and Materials, 2004. 


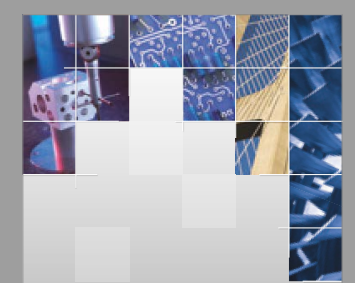

\section{Enfincering}
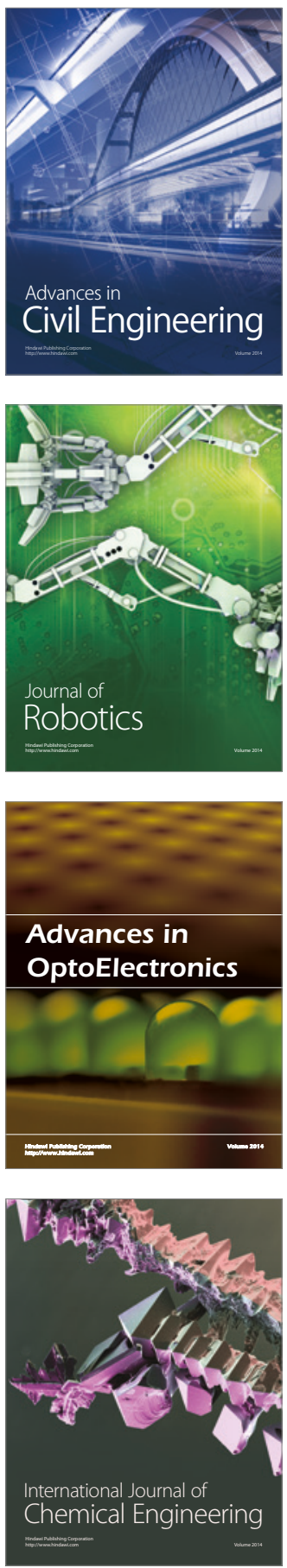

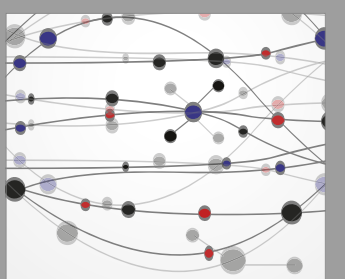

The Scientific World Journal

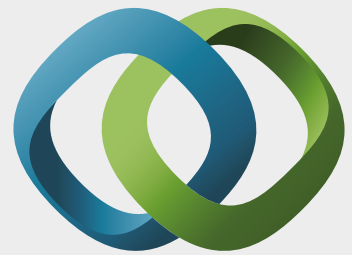

\section{Hindawi}

Submit your manuscripts at

https://www.hindawi.com
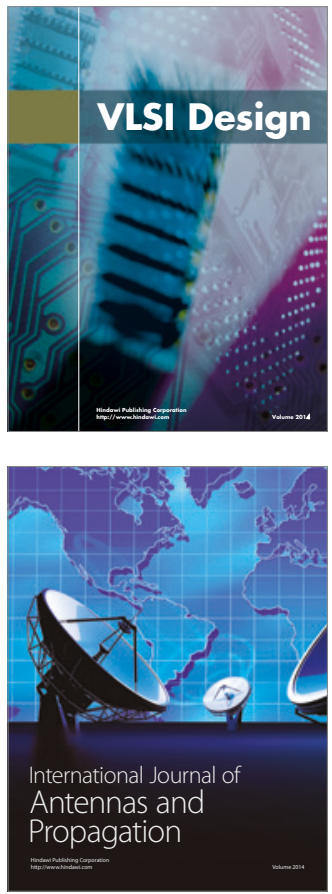

\section{Rotating}

Machinery
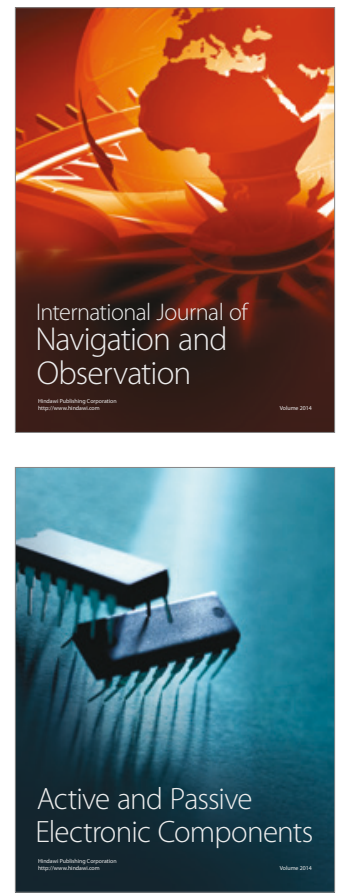
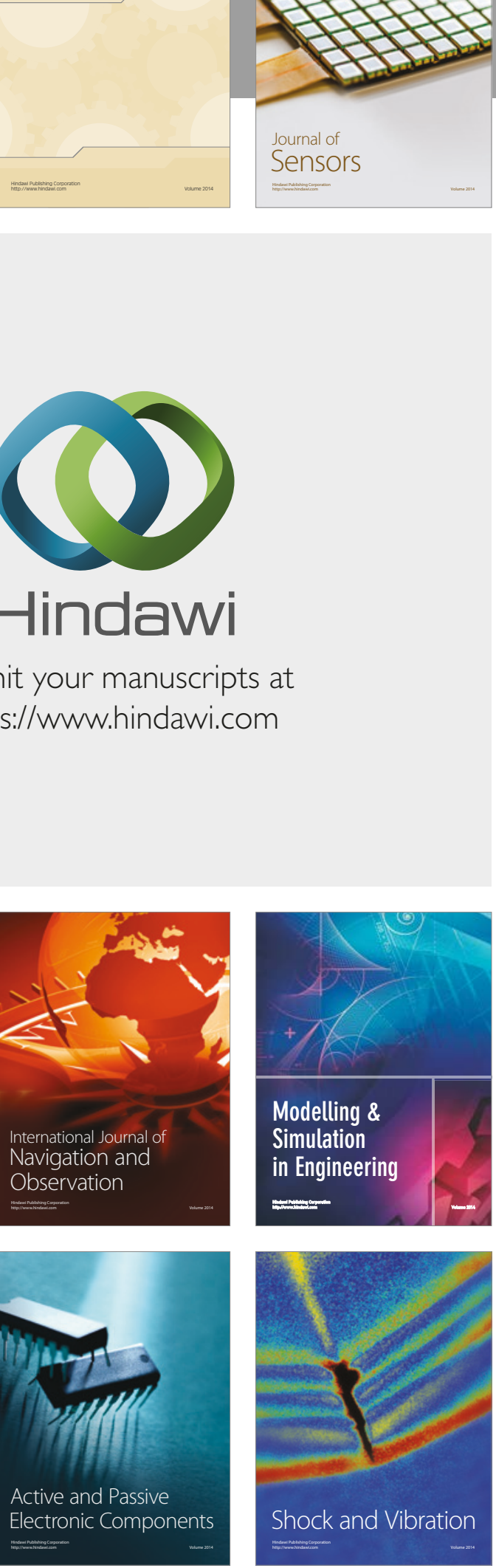
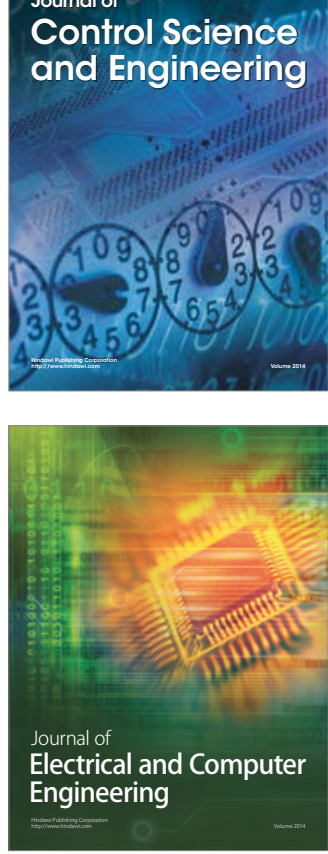

Distributed

Journal of

Control Science

and Engineering
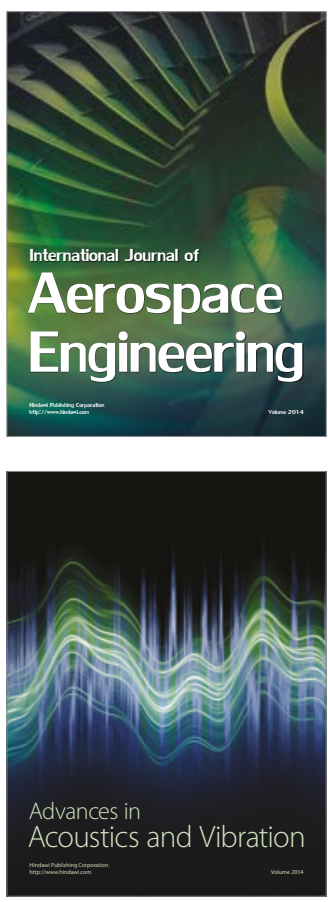

Sensor Networks 